\title{
The Perverse Consequences of Policy Restrictions in the Presence of Asymmetric Information
}

\author{
Rafael Hortala-Vallve \\ London School of Economics and Political Science \\ r.hortala-vallve@lse.ac.uk \\ Valentino Larcinese \\ London School of Economics and Political Science \\ v.larcinese@lse.ac.uk
}

\begin{abstract}
Institutions have the power to limit a government's policy options. Policy restrictions are often used as solutions to coordination failures or time inconsistency problems. However, policy constraints can have significant drawbacks and these disadvantages have, to date, been overlooked in the literature. When institutional constraints tie a government's hands, citizens will have less incentive to become informed about politics and participate in collective decision-making. This is because policy restrictions lower the private returns of political information. A fiscal policy restriction, for example, may decrease redistribution by lowering a poorer voters' acquisition of political information. We illustrate our theoretical findings with numerical simulations and find that in one in three cases these policy restrictions make poorer voters worse off.
\end{abstract}

\section{INTRODUCTION}

Restrictions to the policies that sovereign nations can implement are increasingly common. Institutional constraints exist both domestically and internationally across a myriad of policy dimensions. The European Union (EU), for example, is responsible for a wide range of policy areas over which member-country governments have little discretion. International institutions, such as the International Monetary Fund (IMF) and the World Trade Organization (WTO), also constrain a sovereign government's policy decisions. The WTO, for example, limits the barriers to trade that member countries can impose on foreign goods and services, and the IMF often requires a country to enact specific policies as a condition of accessing their funds. Many governments also face domestic limitations on their policy choices. Some policy areas, for example, are the exclusive responsibility of unelected bodies such as central banks. Other policies may be written directly into a country's constitution making them particularly immune to government action. Additional domestic constraints can include a super-majority requirement for changes to the status quo or automatic rules to replace the discretion of elected representatives. 
Such institutional restrictions are often commended as solutions to perennial political challenges. Restrictions can help solve time-inconsistency problems on the part of policy-makers, thus generating credible commitments (Kydland and Prescott 1977, Persson and Svensson 1989, Alesina and Tabellini 1990). Policy restrictions can also generate higher levels of general welfare by reducing political business cycles (Nordhaus 1975). In the case of international institutions, coordinating the action of member states is often the very reason for the existence of policy restrictions. The benefit of such restrictions is to overcome coordination failures thus helping to reach more desirable outcomes for all members.

Although policy restrictions are usually commended as solutions to fundamental political problems, they can have important disadvantages. One drawback is that they may generate a "democratic deficit", whereby policies are not chosen by citizens through a process of democratic deliberation and decision-making (Dahl 1999). The existence and consequences of a democratic deficit have been debated predominantly in the case of the EU (Hix 2008, Moravcsik 2004, Follesdal and Hix 2006) but similar arguments have also been made for many international organizations. ${ }^{1}$ Independent central banks have also been criticized for concentrating vast powers "in a body free from any kind of direct, effective political control". ${ }^{2}$

Our study takes seriously the idea that democratic deficits matter for public policy. To this end we develop a theoretical model that investigates the effects of policy restrictions imposed by unelected international bureaucrats on sovereign governments. The key insight of our model is that, although policy restrictions are intended to help the poor, they might actually make them worse off. This result is obtained in three steps. First, the fact that an elected government is required to spend above a certain threshold reduces the value that voters place on acquiring political information, as the range of policies the government can implement is reduced. Second, this effect (reduced information acquisition) is stronger for poor voters than it is for better off citizens, due to decreasing returns of information. Third, given the reduced responsiveness of poor voters, electorally minded governments may rationally reduce pro poor spending: the net effect on the poor can be negative when the spending floors are not binding.

The core insights of our model are tested in various simulations. We first run a set of simulations to understand the way in which policy restrictions have perverse consequences when the population is uncertain about the level of inequality in society. We later run a million iterations of our algorithm drawing our simulation parameters randomly from the relevant ranges. We find that one in three cases (where policy restrictions limit the policies of elected governments) the policy restriction has perverse consequence for the poorer citizens who subsist on welfare payments. The rationale for this is that spending floors induce subjects to acquire information less frequently, and under

\footnotetext{
${ }^{1}$ Using the words of Moravcsik, it is hard to "think of a single application of democratic standards to an international organization - whether the European Union, the International Monetary Fund (IMF), the World Trade Organization (WTO), or even the United Nations - that does not conclude with a serious criticism of the organization" (Moravcsik, 2004, p. 337).

${ }^{2}$ Friedman (1968), p. 188.
} 
certain conditions, minimum spending thresholds can have perverse consequences. The implication is that spending floors may reduce the amount of money governments spend on pro poor programs because voters devote less attention to the policies enacted by governments. Consequently, policy restrictions may worsen existing democratic deficits by reducing a citizen's incentive to acquire political information and participate in collective-decision making.

Our conclusion is not that policy restrictions are always inadequate, but rather that once the idea of a democratic deficit is taken into account, limiting the actions of governments might have undesirable consequences. While the literature that highlights the advantages of the restrictions is relatively abundant, the drawbacks have rarely been analysed. We provide a first step in that direction.

\section{Political information as a PRivate Good}

Our point of departure is the idea that information about politics can be useful for private decisionmaking and not just for voting. In his classic work An Economic Theory of Democracy, Anthony Downs (1957) suggests that, "since the odds are that no election will be close enough to render decisive the vote of any one person, or the votes of all those he can persuade to agree with him, the rational course of action for most citizens is to remain politically uninformed".

Downs' argument, like all the subsequent literature on rational ignorance, separates the homo oeconomicus from the homo politicus, neglecting the idea that information that may be relevant for voting decisions can also be acquired for other purposes. For example, information about tax rates can be used to determine one's optimal labour supply and investments; information on the quality of public services can be useful to decide whether it is worthwhile using privately available alternatives. At the same time, being informed on these matters, and on the reforms that are being discussed and/or implemented, generates awareness of current policy-making, and helps citizens evaluate the performance of current administrators. Political information can also be acquired before elections to form more accurate expectations on future taxes, spending, regulations etc. In summary, the collective action problem behind the rational ignorance paradox may not be as severe as envisaged by Anthony Downs because political information is, to a certain extent, a private good. In our view, ordinary citizens may be informed on political matters because (1) political information can be useful for political decision-making and because (2) political information can be useful for private decision-making (e.g. market interactions). The existing literature has widely considered and analyzed the first motive but has largely neglected the second motivation.

The implications analyzed in this paper stem from the fact that acquiring a piece of information has fixed costs yet it yields higher returns to richer individuals. This generates an asymmetric distribution of political knowledge whereby richer voters can be expected, ceteris paribus, to be better informed. Empirical studies support this claim: income is an important explanatory variable for political knowledge, even controlling for age, education and other variables that are positively 
correlated with it. ${ }^{3}$ In our model, the voter decides whether to become informed about political matters or not according to his private returns to information. Prato and Wolton (2014 and 2015) analyse in detail the decision of how much information the voter is willing to obtain and how this depends on partisan and candidate characteristics.

\section{Political information, turnout and Public policies}

Heterogeneous returns to information constitute another key step in our argument. Arrow (1986) provides a model where heterogeneous incentives to acquire information lead to an increase in income inequality via portfolio allocation choices. ${ }^{4}$ The idea that increasing returns to information can alter political equilibria has been introduced by Larcinese (2005), who derives some novel theoretical results on the politics of redistribution and, in particular, that an increase in inequality does not imply an increase in redistribution since it induces more dispersion in political awareness and responsiveness.

We incorporate this thinking in the theory of the size of government by Meltzer and Richard (1981). We think of voters as individuals that vote upon their preferred level of taxation (and redistribution) and simultaneously adopt optimal labor-leisure. When choosing the optimal size of government, voters rationally anticipate the dissuasive effect of taxation on their fellow citizens' decision to work. To this classic model we add asymmetric information: voters only learn about the exact policies advocated by the political parties and the overall economic/political conditions if they acquire (costly) information. ${ }^{5}$

Another important building block for our argument is the idea that political participation affects public policy. While we focus on information and responsiveness to platforms, most previous research has been dedicated to turnout and consistently finds a relationship between turnout patterns and public policy. Starting with the seminal study of Wolfinger (1980), a vast empirical literature consistently finds positive correlations between turnout and individual characteristics such as income and education. Hence, low voter turnout is likely to imply a socioeconomically biased turnout (Rosenstone and Hansen, 1993) which, in turn, can influence the identity and responsiveness of public policy-makers. Evidence in support of this hypothesis has been found by numerous scholars who have shown, for example, that social spending is positively affected by aggregate turnout (Peterson and Rom,1989; Hicks and Swank, 1992; Levitt and Snyder, 1995; Lindert, 1996; Stromberg,

\footnotetext{
${ }^{3}$ See for example Hortala-Vallve and Esteve-Volart (2011) on American voters and Larcinese (2007b) on British voters.

${ }^{4}$ Verrecchia (1982) analyzes a model where agents may acquire private signals about the returns of stocks on top of what equilibrium prices already reveal.

${ }^{5}$ This aspect relates to a number of papers that consider asymmetric information in spatial models of voting. Ledyard (1984), for example, presents a model of spatial electoral competition where each voter is uncertain about the preferences and cost of voting of other voters, and where abstention is admitted. In McKelvey and Ordeshook (1984) some voters are uninformed about the candidates' positions, but they know the preferences of the various subgroups in the population so perfect information is not a necessary condition to apply the median voter theorem. Stromberg (2004) introduces mass media as information sources in a probabilistic voting model: since some voters are more valuable than others to advertisers they get better coverage of the issues of their interest.
} 
2004; Larcinese, 2007a), by lower-class mobilization (Hill and Leighley, 1992, and Hill, Leighley and Hinton-Andersson, 1995), and by the extension of the voting franchise (Husted and Kenny, 1997). Empirical research has also established a causal link between political knowledge and turnout, hence lending further credit and providing empirical support to the mechanism illustrated in this paper (Lassen, 2005; Larcinese, 2007b).

\section{A SIMPLE MODEL}

There is a continuum of voters with a strictly concave utility function for consumption and leisure, $u(c, l)$. In order to keep things simple, we further assume that the utility function is Cobb-Douglas with marginal rate of substitution $\alpha \in(0,1)$. Formally,

$$
u(c, l)=\alpha \ln c+(1-\alpha) \ln l .
$$

Voters are endowed with a unit of time which they need to allocate between labor and consumption. They differ in their marginal productivity: a unit of labour yields $w$ units of consumption (we are assuming the wage $w$ is equal to the marginal productivity of the voter). Given a leisure level $l$, disposable income is equal to $y=w(1-l)$. A fraction $t \in(0,1)$ of a citizen's income is paid in taxes in order to finance a lump-sum per capita transfer $T$. There is no saving so an individual with marginal productivity $w$ has the following disposable income:

$$
c=(1-t) w(1-l)+T .
$$

Voters maximise their utility given a tax rate $t$ and redistribution $T$ :

$$
\max _{l \in[0,1]} U_{w}(l, t, T)=\alpha \ln ((1-t) w(1-l)+T)+(1-\alpha) \ln l .
$$

Following the work by Meltzer and Richards we know that disposable income is increasing in the productivity of the voter. Redistribution is produced with constant returns at unitary cost and, assuming that the budget of the public sector is balanced, we have

$$
T=t \int w(1-l) f(w) d w
$$

where $f(w)$ is the density function of the wage/productivity rate in the population.

The assumption of balanced budget implies that the policy space is unidimensional, since each level of $T$ corresponds to a unique tax rate and vice-versa. Given that leisure is a normal good we have that there is a unique equilibrium in which the individual choice of leisure, the tax rate and the lump-sum redistribution are uniquely determined. Following Roberts (1977), we know that if redistributive preferences of voters are monotonically related to their wage rate (which is the case given that pre-tax income is monotonically increasing with productivity), then a Condorcet winner exists and coincides with the preferred tax rate of the voter with median wage rate. 
We extend the Meltzer-Richards model by assuming that there are two possible wage rate distributions: $f_{1}$ with probability $p_{0}$ and $f_{2}$ with probability $\left(1-p_{0}\right)$. Voters know their own $w$ but can only form expectations on the wage rate distribution. After observing her own wage rate each voter updates the probability of distribution $f_{1}$ to $p \cdot{ }^{6}$ It is not important for our analysis to describe the updating process used by the voter. Nevertheless, to predict or know the wage distribution is important for individual voters because the distribution of wages determines the equilibrium tax rate and equilibrium level of redistribution which is key to compute the individual's optimal choice of leisure.

The size of government is determined by majority voting. There are two parties $(L$ and $R)$ competing for office. They can commit to their platforms and maximize expected plurality. In other words, the objective of parties is to win elections and they announce platforms in order to achieve this goal. All the parties' platforms $\left(t_{L}\right.$ and $\left.t_{R}\right)$ are announced but a voter observes them only when she incurs the costs of becoming informed $k>0$. By incurring these costs, voters also become informed about the wage distribution and so can anticipate the level of redistribution of each platform. This cost is not necessarily a monetary cost, and can reflect the time and effort as well as the money required to acquire information about the political and economic environment. Parties always learn the distribution of the wage rate.

We find the Perfect Bayesian Equilibrium of a game with the following timing: ${ }^{7}$

(1) Nature selects one of the two wage distributions. Political parties observe the wage distribution. Voters privately observe their own wage realization (and update their beliefs on the wage distribution following Bayes rule).

(2) Parties simultaneously announce their platforms. Citizens decide whether they become informed at a cost $k$. They then supply labour and cast their votes on the basis of the information they have. We assume that uninformed voters abstain. ${ }^{8}$

(3) The winning party implements the announced platform and citizens' payoffs are realized.

4.1. The private value of political information. In solving our game, the central question is to compare the utility of an informed citizen with that of an uninformed one. The difference is that an informed citizen can make her labour supply contingent on better information. Instead, an uniformed citizen can only base her decision given her posterior belief of the current distribution. Since this model retains all the classic assumptions of the Downsian electoral competition model, it should not be surprising that, as will be shown later, the parties in equilibrium propose identical platforms. Hence, informed voters know the tax rate and the level of the public transfer, and can

\footnotetext{
${ }^{6}$ For simplicity we assume that all voters hold the same posterior belief. This will not always be true as voters might update their prior after privately observing their own wage. However, introducing different posterior beliefs terribly complicates our analysis and veers away from our main message. We believe all our results hold true as long as there is not much difference between the prior and posterior beliefs of any voter.

${ }^{7}$ Analysing the conditions under which an equilibrium to our game exists is out of the scope of the present paper. Instead, in what follows we characterise the properties of an equilibrium when it exists.

${ }^{8}$ All results hold true if uninformed citizens vote for either party with equal probability.
} 
supply labor optimally. We denote the optimal leisure decision of an informed voter when the wage distribution is $f_{i}$ as $l_{i}$ (for $i=1,2$ ).

Instead, for an uninformed voter the optimal leisure decision $l_{u}$ depends on the posterior belief about the wage distribution and her rational anticipation of the equilibrium policies chosen by political parties:

$$
\begin{aligned}
\max _{l \in[0,1]} \quad p\left(\alpha \ln \left(\left(1-t_{1}\right) w(1-l)+T_{1}\right)+(1-\alpha) \ln l\right)+ \\
+(1-p)\left(\alpha \ln \left(\left(1-t_{2}\right) w(1-l)+T_{2}\right)+(1-\alpha) \ln l\right)
\end{aligned}
$$

where $t_{i}$ and $T_{i}$ are the equilibrium government policies when the wage distribution is $f_{i}$. The following definition formally describes the value of information.

Definition. The expected value of observing the platform announcements is given by

$$
\Delta(w)=p\left[U_{w}\left(l_{1}, t_{1}, T_{1}\right)-U_{w}\left(l_{u}, t_{1}, T_{1}\right)\right]+(1-p)\left[U_{w}\left(l_{2}, t_{2}, T_{2}\right)-U_{w}\left(l_{u}, t_{2}, T_{2}\right)\right]
$$

The value of information is always non-negative: when informed, the voter is maximising two objective functions whilst perfectly knowing the size of government while; when un-informed, the voter is maximising a convex combination of the previous two objective functions. Given that information is not freely available, only the voters whose value of information exceeds the cost $k$ will acquire information and vote. ${ }^{9}$ The key result of our paper shows that the value of information increases in the wage rate of the voter.

Proposition 1. The value of observing the platform announcements is increasing in the marginal productivity of the voter, $\frac{\partial \Delta(w)}{\partial w}>0$. This implies that (1) only sufficiently productive voters acquire information; (2) all other things being equal, decreasing the value of information decreases voter turnout.

This proof can be found in the Appendix. It relies on comparing the first order conditions that determine the optimal leisure decisions with the partial derivative of the value of information with respect to the marginal productivity of the voter. The intuition behind the result is much simpler than the algebraic intensive proof: more productive voters have more to lose from not knowing the exact tax rate when deciding upon their optimal leisure decision. This implies that there is a threshold $\hat{w}$ that separates the uninformed $(w<\widehat{w})$ from the informed $(w>\widehat{w})$ voters. ${ }^{10}$

\footnotetext{
${ }^{9}$ Note that we are assuming that the costs of acquiring information are quasi linear when other monetary costs enter through the consumption part of the Cobb-Douglas utility. We follow this route to simplify the exposition of our results but our results are robust to considering an alternative specification in which $U_{w}(l, t, T)=$ $\alpha \ln ((1-t) w(1-l)+T-k)+(1-\alpha) \ln l$. The richer or more productive a citizen is, the lower the marginal cost of getting informed (Cobb-Douglas has decreasing marginal utility); this implies that when subtracting the costs of information from the consumption of the citizen, we obtain that poorer individuals are less willing to assume these costs and the benefits of acquiring information to these voters is also smaller.

${ }^{10}$ Throughout we assume that $\widehat{w}$ is an interior solution. When the costs of voting are small (large), or the value of information is large (small) we could obtain situations in which everyone (no one) voted. These cases are
} 
The second part of the proposition follows immediately from the fact that voters only vote when they acquire information and that they acquire information only when the benefits from doing so outweigh the costs. ${ }^{11}$

By knowing the optimal behaviour of voters we can solve the political competition stage of our game. Recall that with full commitment to platforms, the policy proposed by the winning party is implemented after the election. If both parties obtain an equal vote share, their policies are implemented with equal probability. Why should voters acquire information if in equilibrium the parties propose identical platforms? The first reason is that it is ex ante unknown where this convergence will happen, because there is uncertainty about the wage distribution and the location of the median voter. Acquiring information will therefore reveal the state of the world and help voters in their private decision of the optimal labour-leisure decision (which depends on the level of taxes and redistribution). Note that knowing the location of the median voter might not suffice as this individual might prefer different taxes when we vary the distribution of wages in society (e.g. the proportion of very rich individuals). For this reason we assume that information acquisition reveals all there is to know about wage distribution so that informed voters can infer the relationship between taxes and redistribution and the preferred levels of taxes by the appropriate median voter. An informed voter always votes for the party whose policy, given the optimal leisure decision, yields maximum utility. The assumptions we make on the utility function imply that there exists a Condorcet winner among informed voters (Roberts, 1977). In other words, both political parties converge to the preferred policy of the median informed voter. In equilibrium there may be some voters who, perfectly anticipating the platform proposed by political parties in the different states of the world, realize it is not acquiring information. Given the results in Proposition 1, we know that there is a threshold in the marginal productivity $(\widehat{w})$ below which voters abstain.

Two conclusions follow immediately from the above analysis. The first is that if the costs of acquiring information are high enough, full information equivalence does not occur: the equilibrium tax rate is lower than the tax that would be chosen by a fully informed electorate. The second is that an increase in the cost of information $k$ decreases the tax rate, by reducing the share of informed voters (which by construction are always richer than informed ones). Hence, obstacles to the free circulation of information that increase acquisition costs, induce lower redistribution.

4.2. The value of information in the presence of a policy restriction. A policy restriction in our setting is modeled as a reduction in the choice set of policy-makers. One such restriction could be establishing a lower bound in the lump-sum redistribution that the elected government needs to implement. This is a typical requirement in recent IMF programs. For example in 2011 more than 80 per cent of agreed programs included floors on pro poor spending and half of these floors were

straightforward so we analyze the most interesting case in which some voters are bound by the costs of information while some others are not.

${ }^{11} \mathrm{~A}$ necessary condition for this result is that the utilities cross derivatives between leisure and consumption are non-zero. If we assumed a quasi-linear utility function we would still obtain that citizens value acquiring information yet the value of information would be the same for all individuals. 
above pre-program spending levels (Clegg 2014). In many circumstances this restriction may only be binding in some states of the world. That being the case, the variance in the possible tax rates by an elected government decreases and, as a consequence, also does the value of information.

Indicating with $\Delta_{r}(w)$ the value of information on platforms under a policy restriction, we have that $\Delta_{r}(w) \leq \Delta(w)$ for all $w$. In the limit, when the policy restriction imposes a unique level of lump-sum redistribution $T$ (and therefore a level of $t$ ), the value of political information is zero.

We consider a policy restriction that imposes a minimum level of lump-sum redistribution, i.e. an $R \geq 0$ such that an elected government can never set $T<R .{ }^{12}$ Denote $\left(T_{i}, t_{i}\right)$ the equilibrium size of government when there is no policy restriction under the distribution of marginal productivities $f_{i}$, for $i=1,2$, and, without loss of generality, assume $T_{1} \leq T_{2}$. There are three possible scenarios. First, when $R \leq T_{1}$, the policy restriction changes nothing because the elected government is implementing a higher level of lump-sum redistribution in both states of the world. Second, when $R \geq T_{2}$, the government is bound by the restriction in all states of the world and voters that prefer higher redistribution are strictly better off. ${ }^{13}$ Finally, the most interesting case occurs when $T_{1}<R<T_{2}$. In this case the government is only constrained in one state of the world. The constraint favors poorer voters who wish for higher redistribution but also has a negative impact on these voters: given that the value of information is marginally reduced, less poor voters cast their vote thus the median voter under the restriction is richer. The lump-sum transfer under distribution $f_{2}$ is therefore lower and there are parameter values for which the poorer voters are ex-ante worse off. The following proposition summarizes our main conclusion:

Proposition 2. Introducing a policy restriction in situations in which voters need to acquire costly information about the policies advocated by political parties can reduce expected utility on the voters that are supposed to benefit from such a policy restriction.

The intuition behind this proposition is simple: the policy restriction reduces the value of information for everybody thus reduces turnout so that the new median voter (under both wage distributions) is now richer. This in turn generates a trade-off: low income voters are better off when the spending floor is binding yet worse off when it is not binding because the median voter votes for a lower level of redistribution. Which effect prevails depends on the parameters of the model and the proof of the Proposition shows that the negative effects can indeed surpass the positive effects of a policy restriction for poorer voters. ${ }^{14}$ In the next Section we run some simulations

\footnotetext{
${ }^{12}$ Given some distributions of marginal productivities, analyzing restrictions on lump-sum redistribution may yield different result than analyzing restrictions on taxes. The implications of such differences are indeed interesting but out of the scope of the current paper.

${ }^{13}$ Under these circumstances all voters would abstain and there is the possibility of multiple equilibria (given appropriate beliefs on parties' actions). Most usual refinements select the equilibrium in which all parties redistribute exactly $R$.

${ }^{14}$ Note that there are some citizens that vote in the absence of the policy restriction yet abstain when the policy restriction is in place. These citizens forego the costs of information acquisition when a policy restriction is introduced. The overall effect of the policy restriction needs to take into account the savings in information acquisition and the change in implemented policies.
} 
to investigate the circumstances under which the perverse outcome materializes. In the appendix we prove the Proposition by showing parameter configurations in which the ex-ante effect of a minimum transfer on poorer voters is negative.

Throughout this section we have assumed that voters are aware of the policy restriction whenever they are in place. This is a plausible assumption given that these restrictions change less frequently than the Government's implemented policies. In the case of international organizations, agreements are not negotiated every year, while taxation and spending levels are typically set in an annual budget. For instance, the $3 \%$ limit to budget deficits in the EU has been in place for almost two decades. Similarly, spending conditions often persist for the life of an IMF loan, which typically span multiple years. For this reason it is more likely that, at any given point in time, voters are aware of the existence of policy restrictions rather than the specific implemented policies.

\section{Are Restrictions so PERVERSe?}

It would be very difficult to directly test our predictions with observational data: it would be almost impossible to isolate the effect of policy restrictions and their effect on voters' incentives to acquire information and on the policies that are offered by politicians in the different states of the world. For this reason, we run two sets of simulations testing the perversity of restrictions in the presence of asymmetric information and whether the indirect effect on the incentives to acquire information reduces the welfare of the most vulnerable citizens.

For the purpose of our simulations we assume that wages are lognormally distributed with mean $\mu_{i}$ and standard deviation $\sigma_{i}$. For simplicity we assume that the relationship between taxes and expenditures follows a Laffer curve parameterized by $T(t)=t(1-t)(A t+B) \bar{w}$, where $\bar{w}$ is the average income in society. ${ }^{15}$ This Laffer curve is well defined whenever $(A t+B)$ is greater than 0 -in our simulations we indeed assume that both $A$ and $B$ are greater than 0 . In what follows we examine the circumstances under which policy restrictions that are supposed to improve some citizens' welfare backfire. In the Appendix we describe our simulation in detail.

The objective of this section is twofold: first, to simulate the consequences of policy restrictions when there is uncertainty about wage inequality by using some reasonable values for the parameters of our model; second, to provide insights about the drivers of the potential perverse effects of the policy restrictions, we run a million iterations of our simulations with randomly drawn parameters. In the classical work by Romer (1975) and Meltzer and Richards (1981), increases in inequality imply a greater dispersion of income and a greater gap between mean and median incomes. This should in turn produce higher levels of redistribution (for a more nuanced view on this relationship see Moene and Wallerstein, 2001). Looking at the issue of inequality when voters are not-perfectly

\footnotetext{
${ }^{15}$ We tried avoiding this further assumption in our simulations but computing the equilibrium mapping between taxes and redistribution was too computationally demanding: recall that the labour decision of any individual depends on taxes and redistribution, and all the citizens' labour decisions in turn influence the amount of revenue that any tax rate raises.
} 
informed, the questions we ask ourselves is (1) how the uncertainty on the level of inequality affects redistribution and (2) what would the impact of policy restrictions be to poorer and less informed voters. Clementi and Gallegati (2006) fit the lognormal distribution to the incomes in the UK, US and Germany finding that the means of the distributions are close to $8(7.83,8.36$, and 8.17 for the UK, US and Germany, respectively) and the standard deviations range between 0.3 and 0.6 (0.3, 0.60 and 0.33 for the UK, US and Germany, respectively).

In our first set of simulations we assume that the distribution of wages follows a lognormal distribution with mean $8\left(\mu_{1}=\mu_{2}=8\right)$ with uncertainty in the standard deviation: we assume the standard deviations can take two values in the interval $[0.1,1.5]$. We assume that the parameters of the Laffer curve are $A=B=1$ (note that these parameters imply that redistribution is maximised at $t=\frac{\sqrt{3}}{3} \approx 0.58$ ), the marginal rate of substitution in the citizen's Cobb-Douglas function is 0.6, and the posterior on the two levels of inequality is flat $(p=0.5)$. For each simulation, we consider a restriction that binds the government's policy in one state of the world when the government proposes differentiated policies in the absence of restrictions. Specifically, when $t_{1}<t_{2}$ the restriction is equal to $R=t_{1} * 0.3+t_{2} * 0.7$. Our simulation takes another step to ensure that the maximum number of iterations are meaningful in our analysis: instead of assuming some specific costs of acquiring information, we compute the costs that are compatible with a level of abstention of $40 \%$ under the first distribution of income when there are no restrictions. This ensures all iterations in our simulation yield interior solutions.

Below we report the loss of introducing policy restrictions to those citizens that subsist on welfare payments. These are the poorer voters whose productivity is sufficiently low to induce them to prefer to devote all their time to leisure and restrict their consumption to the redistributive transfers $T_{i}$. Following our notation these are the voters whose productivity is smaller than $\left(\frac{T_{i}}{1-t_{i}} \cdot \frac{1-\alpha}{\alpha}\right)$. Specifically, the figure below depicts the change in utility induced by the restriction on poorer voters, i.e. the difference between their utility when there is no restriction and their utility with a restriction: the vertical axis depicts the following function $0.3 * \ln \left(\frac{T_{1} \cdot T_{2}}{T_{1}^{R} \cdot T_{2}^{R}}\right)$.

We can observe that there are indeed perverse consequences of imposing policy restrictions when the two possible values of the standard deviation are very different. Recall that different levels of inequality imply big differences in the society's average income $\left(\bar{w}_{i}=\exp \left\{\mu_{i}+\frac{\sigma_{i}^{2}}{2}\right\}\right)$ which in turn affect the citizen's preferred tax rate and labour/leisure decisions. Moreover differences in inequality might also imply large variations in the location of the median voter when the level of abstention changes. In order to analyse the role of these differences, we focus our attention on the following pair of standard deviations: $\sigma_{1}=0.5$ and $\sigma_{2}=1.3$. In these circumstances, the absence of restrictions yields the following two equilibrium tax rates: .432 and .489 (under distributions 1 and 2, respectively). The level of redistribution is equal to 1187 and 2870 , respectively, and the marginal citizen (who is indifferent between voting and abstaining) has an income of 2626. The optimal leisure decisions of the marginal citizen testify to the importance of information: when informed, she would optimally choose to devote 0.72 fraction of her time to leisure under the first 


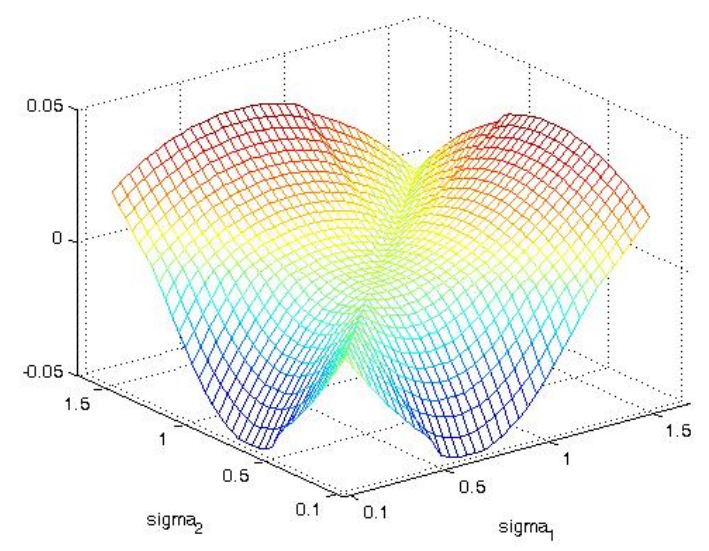

Figure 1. Poorer citizen's expected utility loss when introducing restrictions.

distribution when she would not work under the second distribution; when uninformed, she would devote 0.82 fraction of her time to leisure.

The second distribution has a higher provision of public goods and taxes: when the median voter under the second distribution of wages is much richer than under the first one, the larger average income in society implies that the median voter in this situation desires higher taxation than the median voter in the previously more egalitarian yet poorer society. When a restriction is raised so that taxation is no lower than 0.4719 , the previous marginal voter is no longer indifferent and strictly prefers to abstain. When the restriction is in place the new marginal voter is wealthier: his wage is 2914. Below we depict the two income distributions and the impact of the restriction on the location of the marginal voter with and without the restriction (the marginal voters are identified by the two vertical dashed lines).

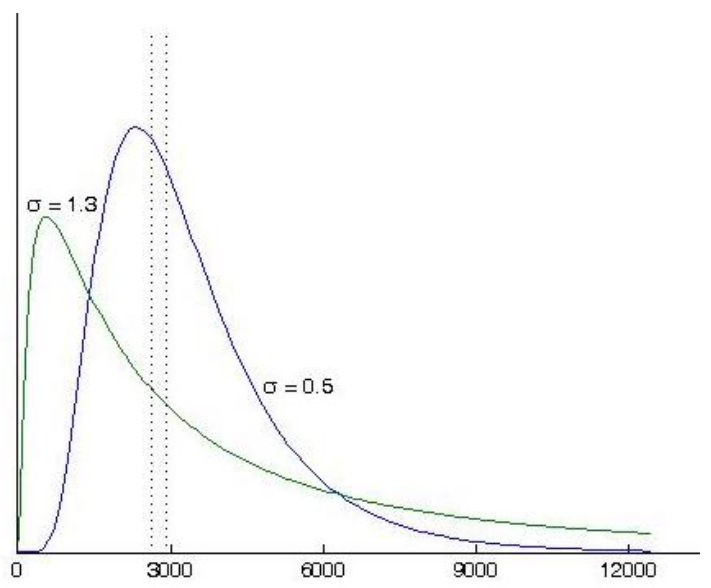

FiguRE 2. Lognormal distribution of incomes when $\mu=8$ and $\sigma_{1}=0.5,1.3$.

(the two dashed lines capture the wage of the marginal voter in the absence $(\mathrm{w}=2626)$ or presence $(\mathrm{w}=2914)$ of a policy restriction $)$ 
In Figure 2 we can see that the increase in abstention (due to the presence of policy restrictions) has a larger effect on the location of the median voter under the first distribution of wages, when $\sigma_{1}=0.5$. Indeed the wages of the median voter under both distributions when there are no restrictions are 3875 and 6628 yet in the presence of restrictions they are 4118 and 7063 . The now richer median voter under the second distribution of wages prefers a lower tax rate and sets it to be equal to the externally imposed restriction: in both states of the world the government implements an income tax of .4719 (the corresponding levels of redistribution are 1239 and 2545).

While we tried to give plausible parameters to our first set of simulations, we remain agnostic as to the appropriateness of some of our assumptions. It is for this reason that in what follows we report results on a million iterations of our simulation in which we randomly choose all parameters. ${ }^{16}$

The results are quite enlightening: in $55 \%$ of observations the introduction of the restriction has no impact because the tax rate under both distributions is exactly the same. Recall that we assume the restriction to be a linear combination of the two tax levels without restriction, it thus follows that when both tax levels coincide there is no binding restriction that applies. Note that under these circumstances some voters might still have incentives to acquire information as the mapping from taxes to redistribution (via the Laffer curve) is affected by the mean income in society which can only be learned by incurring the costs of information. Among the situations in which the restriction is binding the restriction has perverse consequences in 37\% of cases (and in $63 \%$ it benefits poorer voters). In other words, in more than a third of cases in which the restriction is binding, the restriction has perverse consequences for those citizens it is supposed to protect. Recall that the restriction increases spending in one state of the world yet decreases it in the other state of the world because the median voter in the second distribution of wages is richer. Furthermore, in $70 \%$ of the cases when the restriction binds, the richer median voter desires a tax level that is exactly equal to the externally imposed policy restriction. In other words, 7 out of 10 situations in which the equilibrium tax rates differed in the absence of a restriction see the same policy in both states of the world after introducing the restriction. Delving deeper into our simulation we can regress the loss to the poorer voters on the various simulation parameters (in what follows we restrict our analysis to the $45 \%$ of observations where the policy restriction binds the elected government).

The key variable in our simulations is the severity of the policy restriction imposed on the elected government. Recall that this is captured by a variable $y \in(0,1)$ such that $R=t_{1} * y+t_{2} *(1-y)$ where $t_{1}$ and $t_{2}$ are the implemented policies in the absence of a restriction and, without loss of generality $t_{1}<t_{2}$. We find that the greater the severity of the restriction the greater the loss to the poorer voters. In other words, the rationale we highlight in our model bites harder the more beneficial the policy restriction is to the poorer voter. We expected this effect would not be

\footnotetext{
${ }^{16}$ All parameters were drawn from a uniform distribution in the following ranges: $A, B, \sigma_{1}, \sigma_{2} \in(0,1.5) ; \alpha, p, y, \in$ $(0,1)$ where $y$ captures the severity of the restriction, more specifically $y$ is such that $R=t_{1} * y+t_{2} *(1-y)$ when $t_{1}<t_{2} ; \mu_{1}, \mu_{2} \in(4,7)$ and finally, the level of abstention under the first distribution when there is no restriction is drawn from the interval $(0,0.6)$.
} 


\begin{tabular}{|c|c|c|c|}
\hline & (1) & $(2)$ & $(3)$ \\
\hline severity of restriction & $\begin{array}{c}0.4466 \\
(0.0015)^{* *}\end{array}$ & $\begin{array}{c}0.0318 \\
(0.0061)^{* *}\end{array}$ & $\begin{array}{c}0.0317 \\
(0.0061)^{* *}\end{array}$ \\
\hline$(\text { severity of restriction })^{2}$ & & $\begin{array}{c}0.4141 \\
(0.0059)^{* *}\end{array}$ & $\begin{array}{c}0.4144 \\
(0.0059)^{* *}\end{array}$ \\
\hline$\alpha$ & $\begin{array}{c}-0.0871 \\
(0.0024)^{* *}\end{array}$ & $\begin{array}{c}-0.0863 \\
(0.0024)^{* *}\end{array}$ & $\begin{array}{c}-0.0879 \\
(0.0024)^{* *}\end{array}$ \\
\hline abstention when no restr. and $f_{1}$ & $\begin{array}{c}-0.1916 \\
(0.0018)^{* *}\end{array}$ & $\begin{array}{c}-0.1862 \\
(0.0017)^{* *}\end{array}$ & $\begin{array}{c}-0.1850 \\
(0.0017)^{* *}\end{array}$ \\
\hline$p$ & $\begin{array}{c}-0.6486 \\
(0.0015)^{* *}\end{array}$ & $\begin{array}{c}-0.6483 \\
(0.0015)^{* *}\end{array}$ & $\begin{array}{c}-0.6481 \\
(0.0015)^{* *}\end{array}$ \\
\hline$\mu_{1}$ & $\begin{array}{c}-0.0087 \\
(0.0007)^{* *}\end{array}$ & $\begin{array}{c}-0.0075 \\
(0.0007)^{* *}\end{array}$ & $\begin{array}{c}-0.0380 \\
(0.0010)^{* *}\end{array}$ \\
\hline$\mu_{2}$ & $\begin{array}{c}0.0086 \\
(0.0007)^{* *}\end{array}$ & $\begin{array}{c}0.0074 \\
(0.0007)^{* *}\end{array}$ & $\begin{array}{c}0.0379 \\
(0.0010)^{* *}\end{array}$ \\
\hline$\sigma_{1}$ & $\begin{array}{c}-0.0082 \\
(0.0011)^{* *}\end{array}$ & $\begin{array}{c}-0.0079 \\
(0.0011)^{* *}\end{array}$ & $\begin{array}{c}-0.0388 \\
(0.0013)^{* *}\end{array}$ \\
\hline$\sigma_{2}$ & $\begin{array}{c}-0.0170 \\
(0.0011)^{* *}\end{array}$ & $\begin{array}{c}-0.0162 \\
(0.0011)^{* *}\end{array}$ & $\begin{array}{c}0.0169 \\
(0.0013)^{* *}\end{array}$ \\
\hline$A$ & $\begin{array}{c}-0.0688 \\
(0.0010)^{* *}\end{array}$ & $\begin{array}{c}-0.0689 \\
(0.0010)^{* *}\end{array}$ & $\begin{array}{c}-0.0688 \\
(0.0010)^{* *}\end{array}$ \\
\hline$B$ & $\begin{array}{c}0.0849 \\
(0.0013)^{* *}\end{array}$ & $\begin{array}{c}0.0846 \\
(0.0013)^{* *}\end{array}$ & $\begin{array}{c}0.0833 \\
(0.0013)^{* *}\end{array}$ \\
\hline$\left|\bar{w}_{1}-\bar{w}_{2}\right|$ & & & $\begin{array}{c}-0.0473 \\
(0.0010)^{* *}\end{array}$ \\
\hline Constant & $\begin{array}{c}0.1434 \\
(0.0048)^{* *}\end{array}$ & $\begin{array}{c}0.2093 \\
(0.0049)^{* *}\end{array}$ & $\begin{array}{c}0.2310 \\
(0.0049)^{* *}\end{array}$ \\
\hline $\begin{array}{l}R^{2} \\
N\end{array}$ & $\begin{array}{c}0.39 \\
445,787\end{array}$ & $\begin{array}{c}0.40 \\
445,787\end{array}$ & $\begin{array}{c}0.40 \\
445,787\end{array}$ \\
\hline
\end{tabular}

TABLE 1. OLS regression on the poorer voter's loss when introducing a restriction Subsample of observations where the policy restriction has an impact on implemented policies (standard errors in brackets; $+p<0.1,{ }^{*} p<0.05,{ }^{* *} p<0.01$ )

monotonic and would only materialize for the lower value of the restriction while the restriction would definitely help poorer voters when $y$ is closer to 1 . However, we see in column (2) of Table (1) that this is not the case as the square of the restriction severity also has a positive coefficient: the lack of flexibility imposed by the restriction appears to exacerbate the negative impact on poorer voters since high tax rates act to reduce the level of taxable income via their negative impact on richer citizens' working hours.

The marginal rate of substitution of the citizen's Cobb-Douglas utility function has a negative impact on the losses: the higher the weight that citizens attach to the consumption end of their utilities, the more likely it is that the median's preferred policy is closer to revenue maximizing tax. 
This implies that restrictions on the tax rate in one state of the world have a lesser impact on the level of taxes in the other state of the world, thus the overall effect for poorer voters is likely to be positive. The level of abstention when there is no restriction also has a negative impact on losses -this variable is an indirect way to consider the costs of acquiring information.

Recall that our simulation relabels the two states of the world so as to ensure that the level of taxes under the distribution of income $f_{1}$ is smaller than level of tax under $f_{2}$. This implies that $p$ captures the posterior belief on the state of the world where the restriction is binding. We observe that the larger its value the more likely it is that poorer voters will benefit from the restriction. This can be explained because larger values imply that when evaluating the impact of the policy on poorer voters there is more weight on evaluating the impact on the first state of the world which is likely to be positive. Finally, given the re-ordering of states of the world, the first state of the world is more likely to have lower values for $\mu$ and $\sigma$. This implies that the coefficients we observe on the parameters of the lognormal distributions capture that bigger differences increase the value of information and thus have a bigger impact in the welfare of poorer voters as we saw in our first set of simulations. Finally, in order to show that these four parameters do not only play a role when determining the difference in mean incomes in both distributions, we control with this latter variable and find very similar results.

\section{Conclusion}

Whether externally imposed by international institutions, or self-imposed by laws and constitutions, the democratic deficit induced by policy restrictions can have perverse consequences. This paper illustrates how a policy restriction can induce lower level of information acquisition and reduced participation by voters, with relevant consequences for social spending and income redistribution. The argument is based on an analysis of the incentives to acquire political information and highlights the importance of political awareness for private decision-making. We also provide a micro-foundation for the idea that the so-called "democratic deficit" induces low participation in political life.

While we have framed our contribution in terms of internationally-imposed minimum spending requirements, we believe that our theoretical argument has more general applications: the advantages of policy restrictions have been defended at large ${ }^{17}$ yet the drawbacks have rarely been analyzed. The purpose of this paper is not to claim that restrictions are always a bad idea but rather that they might have unintended consequences that are worth considering. The merits and drawbacks

\footnotetext{
${ }^{17}$ For a recent example, see Wyplosz (2005), who proposes the creation of independent Fiscal Policy Committees, with a clear target in terms of debt level, similar to the UK's Monetary Policy Committee.
} 
of policy restrictions should be considered case by case. Current research, however, has devoted no attention to such potential drawbacks and therefore tends to be biased in favor of rules, independent agencies, constitutional restrictions and, in general, limitations to the range of policies that governments can implement at their discretion. Having fully empowered governments has important advantages that have been ignored for too long in the literature on "rules versus discretion". Of particular importance is the possibility for citizens to be involved in public deliberation and decision-making, with the added benefit of a public discussion of policy-issues that, when delegated to technocrats, are instead often removed from public attention. The framework presented in this paper shifts the terms of this trade-off towards having empowered governments whose actions are communicated transparently to their voters instead of using policy restrictions. 


\section{REFERENCES}

Alesina, Alberto and Tabellini, Guido 1990. A Positive Theory of Fiscal Deficits and Government Debt, The Review of Economic Studies, Vol. 57, No. 3, pp. 403-414

Arrow, Kenneth 1986. The Demand for Information and the Distribution of Income, Institute for Mathematical Studies in the Social Sciences, Stanford University, Technical Report n. 494

Clegg, Liam 2014. Social spending targets in IMF concessional lending: US domestic politics and the institutional foundations of rapid operational change, Review of International Poltical Economy, Vol. 21, Issue 3, pp 735-763

Clementi, F and Gallegati, M. 2005. Pareto's Law of Income Distribution: Evidence for Germany, the United Kingdom, and the United States, in Econophysics of Wealth Distributions. Milan, Springer-Verlag Italia, pp. 3-14

Dahl, Robert 1999. Can International Organizations Be Democratic? A Skeptic's View, in Ian Shapiro and Casiano Hacker-Cordon (eds. "Democracy's Edges". Cambridge: Cambridge University Press, pp. 19-36

Downs, A. 1957. An Economic Theory of Democracy. Addison-Wesley

Follesdal, Andreas and Hix, Simon 2006. Why there is a democratic deficit in the EU, Journal of Common Market Studies, Vol. 44, Issue 3, pp. 533-562

Friedman, Milton. 1968. Dollars and Deficits. Englewood Cliffs, NJ: Prentice-Hall.

Hicks, Alexander and Swank, Duane. 1992. Politics, Institutions, and Welfare Spending in Industrialized Democracies, 1960-1982, American Political Science Review, Vol 86, No. 3, pp. 658-674

Hill, Kim and Leighley, Jan 1992. The Policy Consequences of Class Bias in State Electorates, American Journal of Political Science, Vol 36, No. 2, pp. 351-365

Hill, Kim, Leighley, Jan and Hinton-Andersson, Angela. 1995. Lower Class Mobilization and Policy Linkage in the US States, American Journal of Political Science, Vol 39, No. 1, pp. 75-86.

Hix, Simon. 2007. What's Wrong with the EU and How to Fix It. Polity Press.

Hortala-Vallve, Rafael and Esteve-Volart, Berta 2011. Voter Turnout in a Multidimensional Policy Space, Economics of Governance, Volume 12, Number 1, pp. 25-49

Husted, Thomas and Kenny, Lawrence 1997. The Effect of the Expansion of the Voting Franchise on the Size of Government, Journal of Political Economy, Vol 105, Issue 1, pp. 54-82

Kydland, Finn and Prescott, Edward. 1977. Rules Rather Than Discretion: The Inconsistency of Optimal Plans, Journal of Political Economy, Vol 85, Issue 3, pp. 473-492

Larcinese, Valentino. 2005. Electoral Competition and Redistribution with Rationally Informed Voters, Contributions to Economic Analysis and Policy, vol.4, n. 1, art. 4.

Larcinese, Valentino. 2007a. Voting Over Redistribustion and the Size of the Welfare State, Political Studies, Vol 55 pp.568-585

Larcinese, Valentino. 2007b. Does Political Knowledge Increase Turnout? Evidence from the 1997 British General Election, Public Choice, Vol 131, Issue 3, pp. 387-411

Lassen, David. 2005. The Effect of Information on Voter Turnout: Evidence from a Natural Experiment, American Journal of Political Science, Vol 49, No. 1, pp. 103-118 
Ledyard, Jonh. 1984. The pure theory of large two-candidate elections, Public Choice, Vol 44, No. 1, pp. 7-41

Levitt, Steven, and Snyder, James. 1995. Political Parties and the Distribution of Federal Outlays, American Journal of Political Science, Vol. 39, No. 4, pp. 958-980

Lindert, Peter. 1996. What Limits Social Spending? Explorations in Economic History, Vol 33, pp. 1-34

McKelvey, Richard and Ordeshook, Peter. 1984. Rational Expectations in Elections: Some Experimental Results Based on a Multidimensional Model, Public Choice, Vol. 44, Issue 1, pp. 61-102

Meltzer, Allan and Richards, Scott. 1981. A Rational Theory of the Size of Government, Journal of Political Economy, Vol. 89, Issue 5, 914-927

Moene, Karl Ove and Wallerstein, Michael. 2001. Inequality, Social Insurance, and Redistribution, American Political Science Review, Vol. 95, No.4., pp 859-874

Moravcsik, Andrew. 2004. Is there a 'Democratic Deficit' in World Politics? A Framework for Analysis, Government and Opposition, Vol. 39, Issue 2, pp. 336-363

Nordhaus, William. 1975. The Political Business Cycle, Review of Economic Studies, Vol. 42, No. 2, 169-190

Persson, Torsten and Svensson, Lars. 1989. Why a stubborn conservative would run a deficit: Policy with time-consistent preferences, Quarterly Journal of Economics, Vol 104, No. 2, 325-345 Prato, Carlo and Wolton, Stephane. 2014. Electoral Unbalance and Democratic Responsiveness, mimeo

Prato, Carlo and Wolton, Stephane. 2015. The Voters' Curses: Why We Need Goldilocks Voters, American Journal of Political Science, forthcoming

Roberts, Kevin. 1977. Voting over Income Tax Schedules, Journal of Public Economics, Vol. 8, $329-340$

Romer, Thomas. 1975. Individual Welfare, Majority Voting, and the Properties of a Lienar Income Tax, Journal of Public Economics, Vol. 4, Issue 2, pp. 163-185

Rosenstone, Steven and John Hansen. 1993. Mobilization, Participation, and Democracy in America. New York: MacMillan Publishing Company.

Stromberg, David. 2004. Mass Media Competition, Political Competition and Public Policy, Review of Economic Studies, Vol. 71, No.1, pp. 265-284

Verrecchia, Robert 1982. Information Acquisition in a Noisy Rational Expectations Economy, Econometrica, Vol 50, No. 6, pp. 1415-1430

Wolfinger, Raymond. 1980. Who Votes?, New Haven: Yale University Press.

Wyplosz, Charles. 2005. Fiscal Policy: Institutions versus rules, National Insitute Economic Review, Vol. 191, No. 1, pp.64-78 